\title{
Relationship of phasic left atrial volume and emptying function to left ventricular filling pressure: a cardiovascular magnetic resonance study
}

Kanna Posina ${ }^{1}$, Jeannette McLaughlin' ${ }^{1}$, Peter Rhee ${ }^{1}$, Laura Li ${ }^{1}$, Joshua Cheng ${ }^{1}$, William Schapiro ${ }^{1}$, Ronald J Gulotta ${ }^{1}$, Andrew D Berke ${ }^{1}$, George A Petrossiann ${ }^{1}$, Nathaniel Reichek ${ }^{1,2}$ and Jie J Cao ${ }^{1,2^{*}}$

\begin{abstract}
Background: Left atrial volume (LAV) and emptying fraction (LAEF) are phasic during cardiac cycle. Their relationships to left ventricular end diastolic pressure (LVEDP) have not been fully defined.

Methods: Forty one patients undergoing clinically indicated left heart catheterization were recruited for same day cardiovascular magnetic resonance (CMR). LAV and LAEF were assessed in cine images using biplane area and length method. Three phasic $L A V$ was assessed at $L V$ end systole $\left(L A V_{\max }\right)$, $L V$ end diastole $\left(L A V_{\min }\right)$ and late $L V$ diastole prior to $L A$ contraction ( $\left.L A V_{a c}\right)$. LAEF was assessed as global LAEF ( $\left.L A E F_{\text {Total }}\right)$, passive (LAEF passive) and active LAEF (LAEF contractile). The relationships of phasic LAV and LAEF to LVEDP were assessed using Receiver operating characteristic comparing areas under the curves (AUC).

Results: The mean age of the patients was 59 years. A history of heart failure was present in 16 (39\%) with NYHA functional class III or IV in 8 (20\%) patients. Average LV ejection fraction was $49 \pm 16 \%$ ranging from $10 \%$ to $74 \%$ and LVEDP by catheterization $14 \pm 8 \mathrm{mmHg}$ ranging from $4 \mathrm{mmHg}$ to $32 \mathrm{mmHg}$. LAV $V_{\text {min }}$ had the strongest association with LVEDP elevation $(>12 \mathrm{mmHg}$ ) (AUC 0.765, $p=0.002$ ), as compared to LAV $\max$ (AUC 0.677, $p=0.074$ ) and $L A V_{a c}$ (AUC 0.735, $p=0.008$ ). Among three phasic LAEF assessed, $L A E F_{\text {Total }}$ had the closest association with LVEDP elevation (AUC 0.780, $p=0.001$ ), followed by LAEF Contractile (AUC 0.698, $p=0.022$ ) and LAEF passive (AUC 0.656, $p=0.077)$.
\end{abstract}

Conclusions: Increased LAV $V_{\min }$ and decreased $L A E F_{\text {Total }}$ have the best performance in identifying elevated LVEDP among three phasic LAV and LAEF analyzed. Future studies should further characterize LA phasic indices in clinical outcomes.

Keywords: Left atrial function, Left atrial volume, Left ventricular filling pressure, Cardiovascular magnetic resonance

\section{Background}

Left atrial (LA) dilatation is found in many conditions, including atrial fibrillation, left ventricular (LV) systolic and diastolic dysfunction, congestive heart failure, and valvular heart disease [1-4]. Increased maximal LA size measured at LV end systole has been associated with cardiovascular morbidity and mortality in population-

\footnotetext{
* Correspondence: Jane.Cao@chsli.org

'St. Francis Hospital, Roslyn, NY, USA

${ }^{2}$ State University of New York, Stony Brook, 100 Port Washington Boulevard, Roslyn, NY 11576, USA
}

\section{Biomed Central}

(c) 2013 Posina et al.; licensee BioMed Central Ltd. This is an open access article distributed under the terms of the Creative Commons Attribution License (http://creativecommons.org/licenses/by/2.0), which permits unrestricted use, distribution, and reproduction in any medium, provided the original work is properly cited. based studies, a finding attributed to the detrimental effect of chronically increased LV filling pressure which results in LA remodeling over time [3,5-8]. LA function has three distinct phases during cardiac cycle: a filling phase during ventricular systole, a conduit phase during early diastolic rapid ventricular filling and an active contraction phase during late diastole [9]. Early reports based on echocardiographic data demonstrated a direct relationship of increased filling pressure to increased LA size and reduced LA function [10]. However, the relationship of 
LA phasic volume and function to LV filling pressure have not been fully defined.

The standard method of determining phasic LA volumes (LAV) is based on a time-volume curve depicting LAV over the entire cardiac cycle. A simpler alternative, which is commonly used in clinical studies, assesses LAV in single-phase analyses characterized by mitral valve position [11-13]. But it is unclear whether the single-phase method provides results comparable to those obtained using the more laborious volume curve approach.

We sought to assess the relationship of phasic LAV and LA function to LV filling pressure and to compare the single-phase LAV method to the standard multiphase method using cardiovascular magnetic resonance (CMR) in a group of patients who underwent clinically indicated right and left heart catheterization.

\section{Methods}

\section{Study population}

The study protocol was approved by the St. Francis Hospital Institutional Review Board. All subjects were prospectively recruited with written consent. There were 41 patients undergoing clinically indicated right and left heart catheterization. Exclusions included atrial fibrillation, impaired renal function with glomerular filtration rate $<45 \mathrm{~mL} / \mathrm{min} / 1.73 \mathrm{~m}^{2}$; claustrophobia; pacemaker/ defibrillator implantation; or other metallic hazards.

\section{Hemodynamics}

LV end diastolic pressure (LVEDP) was obtained during left heart catheterization following standard clinical protocol. Hemodynamic tracings obtained during quiet respiration were recorded and stored electronically. Two experienced cardiologists reviewed tracings and the values of LVEDP were determined by consensus. To match the inspiration breath-hold during CMR image acquisition LVEDP at inspiration was used.

\section{CMR}

All subjects underwent CMR in a $1.5 \mathrm{~T}$ Avanto scanner (Siemens) using 8-element phased array surface coil. Steady-state free precession (SSFP) cine images were acquired during inspiratory breath-holds with retrospective ECG gating in long axis 2-, 3- and 4-chamber views. A stack of 8-mm thick short axis images was obtained with 2-mm gaps. The average field of view was $240 \mathrm{~mm}$, echo time $1.3 \mathrm{~ms}$, repetition time $3.1 \mathrm{~ms}$, flip angle $70^{\circ}$, matrix $192 \times 154$ yielding an in-plane resolution of $1.6 \times 1.3 \mathrm{~mm}$ and temporal resolution of 30-40 ms. The average number of phases was 20 to 30 , varying by heart rate to reach consistent temporal resolution.

\section{Image analysis}

Volumetric short axis cine images were analyzed using commercially available software (QMass by Medis, Netherland). Left and right ventricular volumes, ejection fraction and myocardial mass were assessed and normalized to body surface area. LAV were calculated using a biplane area and length method following the formula: $0.85 \times \mathrm{A} 1 \times \mathrm{A} 2 / \mathrm{L}$, where $\mathrm{A} 1$ and $\mathrm{A} 2$ were areas measured by planimetry in 2- and 4-chamber views, respectively and $\mathrm{L}$ was the length of LA perpendicular to the center of mitral annulus in the 4-chamber plane (Figure 1) [13]. Due to inconsistent presence of the LA appendage in the 2 chamber view we excluded LA appendage from all analyses. LAV was assessed at LV end systole $\left(\mathrm{LAV}_{\max }\right)$, at $\mathrm{LV}$
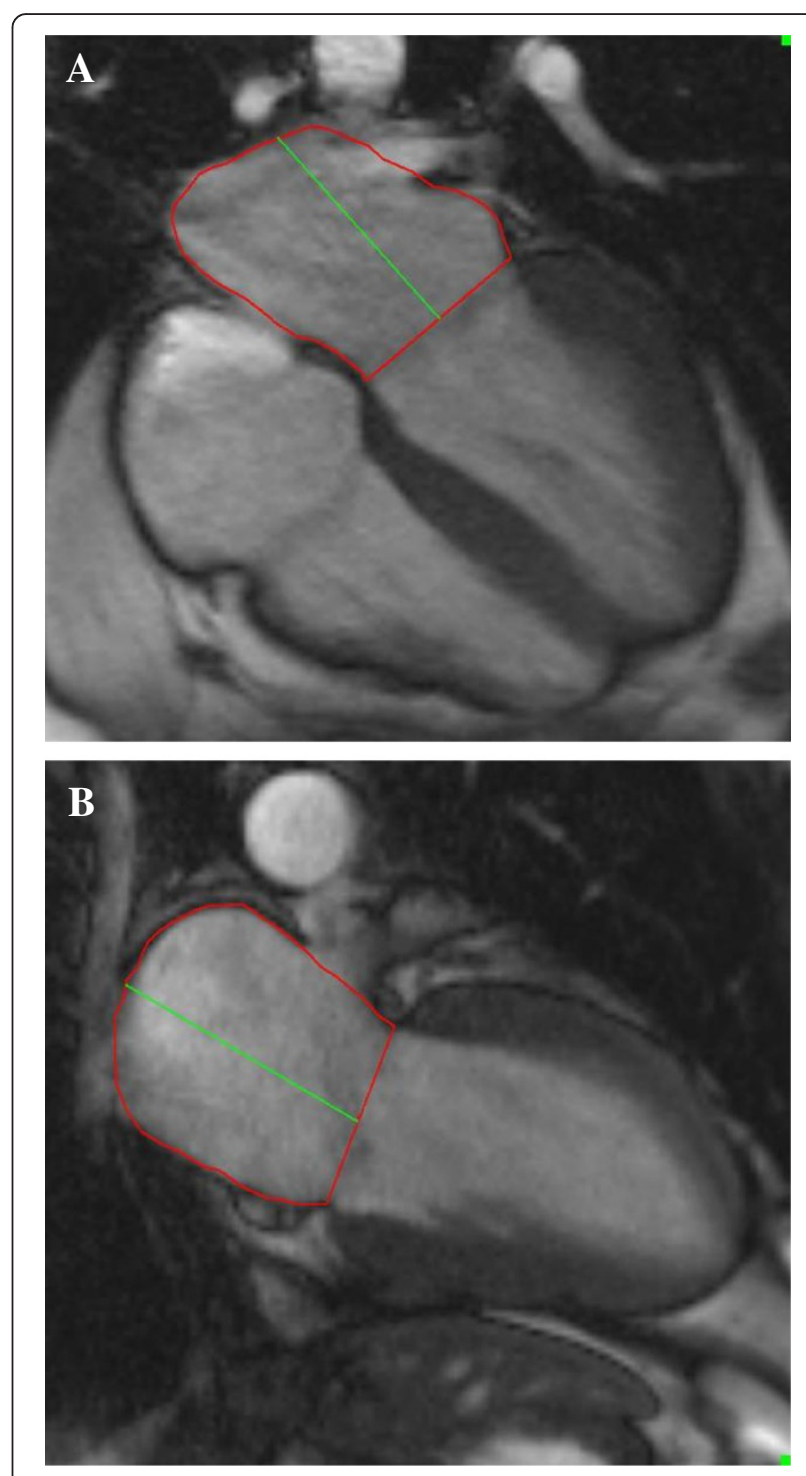

Figure 1 Left atrial area and length assessment using the 4 (A) and 2 (B) chamber views at left ventricular end systole. 


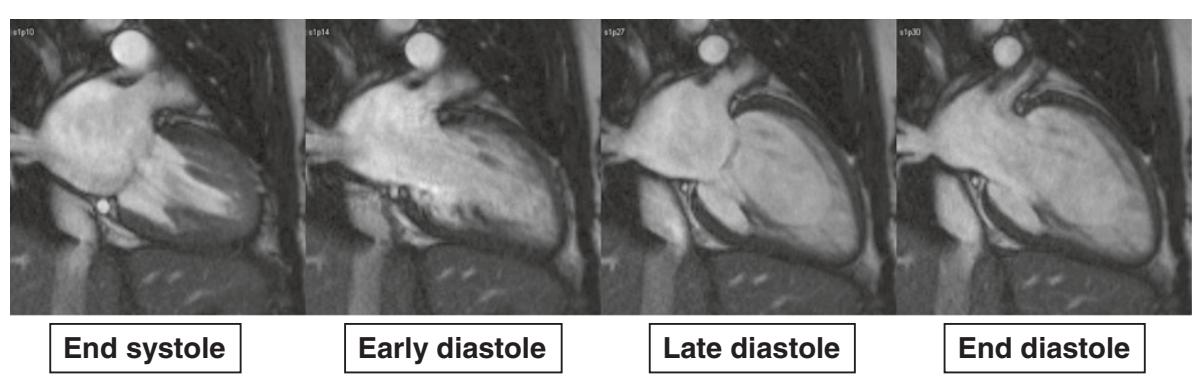

Figure 2 Illustrations of left atrial phasic changes on MR cine images during cardiac cycle when atrial size is at the largest during end systole and smallest during end diastole. The left atrial precontractile phase is determined at the late diastole when mitral valve is nearly closed before it opens again after atrial contraction.

late diastole just before LA contraction $\left(\mathrm{LAV}_{\mathrm{ac}}\right)$ and $\mathrm{LV}$ end diastole $\left(\mathrm{LAV}_{\min }\right)$ (Figure 2) $[8,12]$. LAV was determined using both single-phase analysis and multi-phase time-volume curves. For the single-phase method, all slices of the 2- and 4-chamber cines were reviewed and
$\mathrm{LAV}_{\max }, \mathrm{LAV}_{\mathrm{ac}}$, and $L A V_{\text {min }}$ assessed at time points just before mitral valve opening, immediately prior to atrial contraction and at the time of mitral valve closure, respectively. Using the multi-phase time-volume curve method data points for $\mathrm{LAV}_{\max }, \mathrm{LAV}_{\mathrm{ac}}$ and $L A V_{\text {min }}$
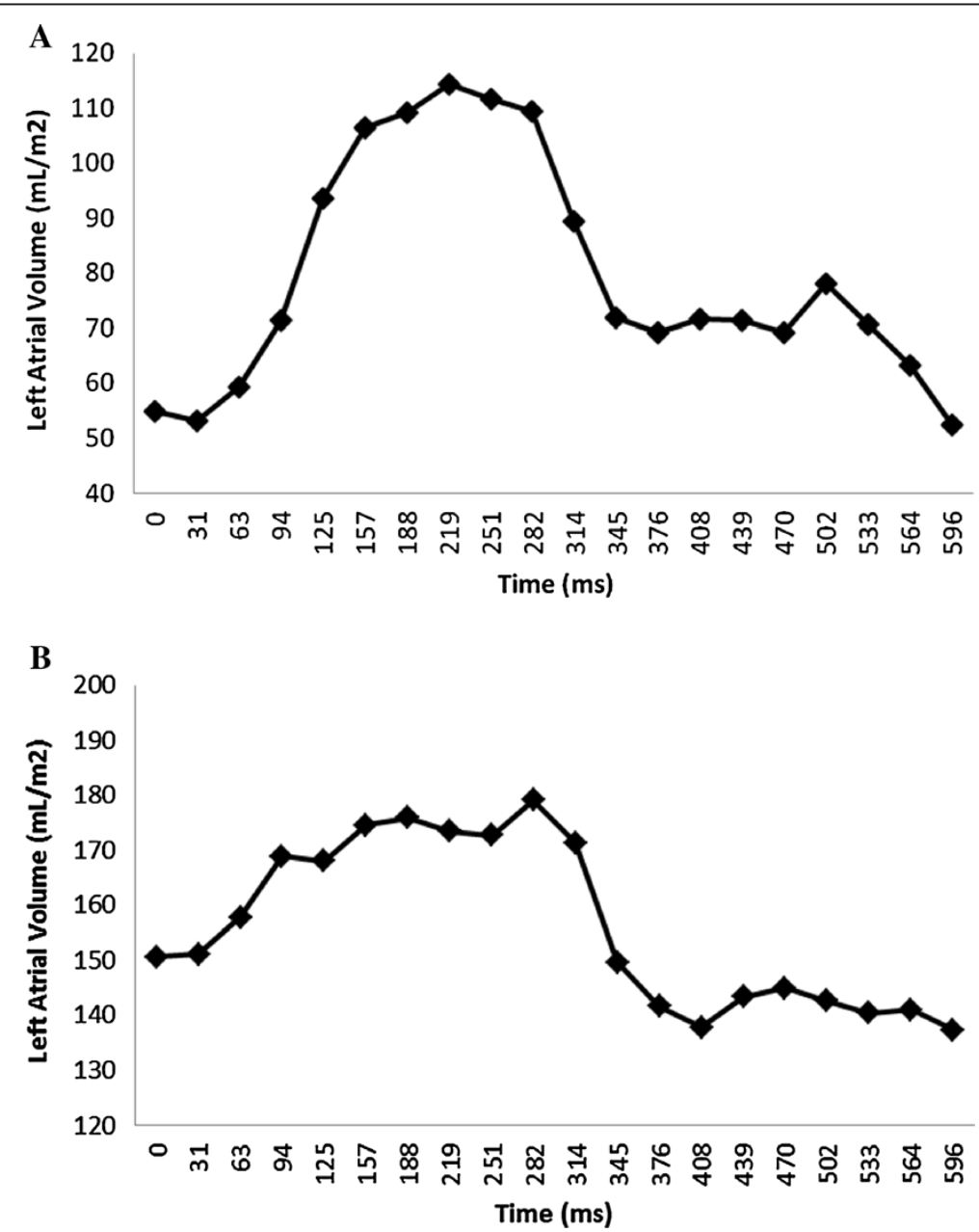

Figure 3 Examples of time volume curves for patient with normal global left atrial emptying function (58\%) and left ventricular end diastolic pressure $(7 \mathrm{mmHg})(A)$ and for patient with reduced global left atrial emptying function (23\%) and elevated left ventricular end diastolic pressure $(32 \mathrm{mmHg})(B)$. 
were defined as the maximum volume during systole, maximum volume prior to atrial contraction and minimum volume at the end of diastole respectively (Figure 3). Inter and intra-observer variability of LAV quantitation was determined in five randomly selected cases for both methods. The intra and inter-observer concordance correlation coefficients were 0.99 and 0.98 for the single-phase method, and 0.92 and 0.90 for multiphase method, respectively. Global emptying function $\left(\mathrm{LAEF}_{\text {Total }}\right)$, passive LAEF ( $\left.\mathrm{LAEF}_{\text {Passive }}\right)$ and active LAEF $\left(\mathrm{LAEF}_{\text {Contractile }}\right)$ were defined as fractional volume changes as follows. $\mathrm{LAEF}_{\text {Total }}=\left(\mathrm{LAV}_{\max }-\mathrm{LAV}_{\text {min }}\right) /$ $\mathrm{LAV}_{\text {max }}, \quad \mathrm{LAEF}_{\text {Passive }}=\left(\mathrm{LAV}_{\text {max }}-\mathrm{LAV}_{\mathrm{ac}}\right) / \mathrm{LAV}_{\text {max }}$ and $\mathrm{LAEF}_{\text {Contractile }}=\left(\mathrm{LAV}_{\mathrm{ac}}-\mathrm{LAV}_{\text {min }}\right) / \mathrm{LAV}_{\text {max }}$, respectively [8].

\section{Statistical analysis}

Categorical variables were expressed as proportions and continuous variables as means \pm standard deviations (SD). Categorical variables were compared using Fisher's exact test and continuous variables using Student's $t$ test. Receiver operating characteristic analysis was performed to evaluate the associations of LAV and LA function variables with LVEDP and areas under the curves compared. Sensitivity testing based on the optimal sensitivity and specificity in Receiver operating characteristic analysis was used to determine the cut points of phasic LAV and LA function in identifying associated elevated LVEDP (> $12 \mathrm{mmHg}$ ). Bland-Altman plots were used to compare LAV measurements derived using single-phase and multi-phase methods. For all statistical analyses, $\mathrm{p}<0.05$ was considered significant. Statistical analysis was performed using MedCalc 11.3 (MedCalc Software, Belgium) and SPSS 17 (SPSS Inc, Chicago, IL).

\section{Results}

The mean age of the patients was 59 years. A history of coronary artery disease was present in $27 \%$ of patients and history of congestive heart failure in 39\%. NYHA functional class III or IV was present in $20 \%$ of patients. Average LV ejection fraction was $49 \pm 16 \%$ ranging from $10 \%$ to $74 \%$ with $32 \%$ of patients having LV ejection fraction $<50 \%$. Mean LVEDP was $14 \pm 8 \mathrm{mmHg}$ ranging from $4 \mathrm{mmHg}$ to $32 \mathrm{mmHg}$. The most prevalent significant valvular dysfunction $(\geq 2+)$ was aortic insufficiency (17\%) followed by mitral regurgitation (12\%) (Table 1).

$\mathrm{LAV}_{\text {max }}, \mathrm{LAV}_{\mathrm{ac}}$ and $\mathrm{LAV}_{\text {min }}$ were strongly correlated with each other $\left(r=0.938\right.$ between $\mathrm{LAV}_{\max }$ and $\mathrm{LAV}_{\mathrm{ac}}$, $r=0.953$, between $\mathrm{LAV}_{\text {min }}$ and $\mathrm{LAV}_{\mathrm{ac}}, \mathrm{r}=0.896$ between $\mathrm{LAV}_{\text {max }}$ and $\mathrm{LAV}_{\text {min }}$, all $\left.\mathrm{p}<0.001\right)$. Each was significantly larger in subjects with elevated LVEDP $(>12 \mathrm{mmHg}$ ) than in those with normal LVEDP ( $\leq 12 \mathrm{mmHg}$ ) (Table 2). Pearson correlation of LAV to LVEDP was modest with correlation coefficient of $0.536(\mathrm{p}<0.001), 0.412(\mathrm{p}=0.007), 0.482(\mathrm{p}=0.001)$
Table 1 Patient characteristics $(\mathrm{N}=\mathbf{4 1})$

Mean \pm SD or $\mathrm{N}(\%)$

Demographics

Age (years)

$59 \pm 15$

Female

15 (37)

Body mass index $\left(\mathrm{kg} / \mathrm{m}^{2}\right)$

$30 \pm 6$

Hypertension

$26(63)$

Hyperlipidemia

$24(59)$

Diabetes

$7(17)$

History of coronary artery disease

$11(27)$

History of heart failure

16 (39)

NYHA functional class III or IV

$9(20)$

\section{Hemodynamics}

Heart rate (beats/sec)

$70 \pm 14$

Systolic pressure $(\mathrm{mmHg})$

$127 \pm 16$

Diastolic pressure $(\mathrm{mmHg})$

$75 \pm 12$

LVEDP $(\mathrm{mmHg})$

$14 \pm 8$

\section{CMR indices}

LV end diastolic volume $\left(\mathrm{mL} / \mathrm{m}^{2}\right)$

$90 \pm 39$

LV end systolic volume $\left(\mathrm{mL} / \mathrm{m}^{2}\right)$

$55 \pm 59$

LV ejection fraction (\%)

$49 \pm 16$

LV Mass Index $\left(\mathrm{g} / \mathrm{m}^{2}\right)$

$68 \pm 29$

RV end diastolic volume $\left(\mathrm{mL} / \mathrm{m}^{2}\right)$

$68 \pm 21$

RV end systolic volume $\left(\mathrm{mL} / \mathrm{m}^{2}\right)$

$35 \pm 21$

RV ejection fraction (\%)

$52 \pm 14$

RV Mass Index $\left(\mathrm{g} / \mathrm{m}^{2}\right)$

$19 \pm 6$

\section{Significant valvular dysfunction $(\geq 2+)$}

Aortic stenosis

Aortic regurgitation

7 (17)

Mitral regurgitation

5 (12)

Tricuspid regurgitation

$1(2)$

Pulmonic regurgitation

$1(2)$

Table 2 Comparisons of LA Indices between subjects with elevated (>12 $\mathrm{mmHg}$ ) and normal LVEDP ( $\leq 12 \mathrm{mmHg})$

\begin{tabular}{lccc}
\hline & $\begin{array}{c}\text { LVEDP } \\
(\mathbf{1 2} \mathbf{~ m m H g}) \\
(\mathbf{N}=\mathbf{1 4})\end{array}$ & $\begin{array}{c}\text { LVEDP } \\
(\mathbf{1 2} \mathbf{~ m m H g}) \\
(\mathbf{N}=\mathbf{2 7})\end{array}$ & p-value \\
\hline $\mathrm{LAV}_{\text {min }}\left(\mathrm{mL} / \mathrm{m}^{2}\right)$ & $35 \pm 20$ & $22 \pm 9$ & 0.016 \\
$\mathrm{LAV}_{\text {max }}\left(\mathrm{mL} / \mathrm{m}^{2}\right)$ & $56 \pm 21$ & $44 \pm 13$ & 0.065 \\
$\mathrm{LAV}_{\mathrm{ac}}\left(\mathrm{mL} / \mathrm{m}^{2}\right)$ & $48 \pm 18$ & $37 \pm 11$ & 0.027 \\
$\operatorname{LAEF}_{\text {Passive }}(\%)$ & $16 \pm 8$ & $16 \pm 8$ & 0.078 \\
$\operatorname{LAEF}_{\text {contractile }}(\%)$ & $25 \pm 12$ & $35 \pm 9$ & 0.029 \\
$\operatorname{LAEF}_{\text {Total }}(\%)$ & $41 \pm 16$ & $51 \pm 10$ & 0.005 \\
$\operatorname{LVEDP}_{(\mathrm{mmHg})}$ & $22 \pm 7$ & $9 \pm 2$ & $<0.001$ \\
\hline
\end{tabular}


for $L A V_{\text {min }}, L A V_{\text {max }}$ and $L A V_{a c}$, respectively. Using ROC analyses, the association with elevated LVEDP was stronger for $L A V_{\text {min }}$ and $L A V_{a c}$ than for $L A V_{\text {max }}$ (Figure $4 \mathrm{~A}-\mathrm{C}$ ). In the sensitivity testing, $\mathrm{LAV}_{\min }$ was more sensitive, while $L A V_{\text {max }}$ and $L A V_{a c}$ were more specific in identifying elevated LVEDP (Table 3). The three LAEF indices correlated with each other moderately $\left(r=0.621\right.$ between $\mathrm{LAEF}_{\text {Total }}$ and $\mathrm{LAEF}_{\text {Passive }}, \mathrm{r}=$ 0.629 between $\mathrm{LAEF}_{\text {Total }}$ and $\mathrm{LAEF}_{\text {Contractile, }} \mathrm{r}=0.581$

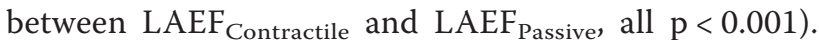
Similar to phasic LAV, all three phasic LAEF indices were lower in subjects with elevated LVEDP than in those without (Table 2). Using ROC analysis LAEF $_{\text {Total }}$ had the strongest association with elevated LVEDP followed by $\mathrm{LAEF}_{\text {Contractile }}$ and $\mathrm{LAEF}_{\text {Passive }}$ (Figure 4D-F). In the sensitivity testing, $\mathrm{LAEF}_{\text {Total }}$ and $\mathrm{LAEF}_{\text {Contractile }}$ were more specific in predicting elevated LVEDP while $\mathrm{LAEF}_{\text {Passive }}$ was more sensitive (Table 3).
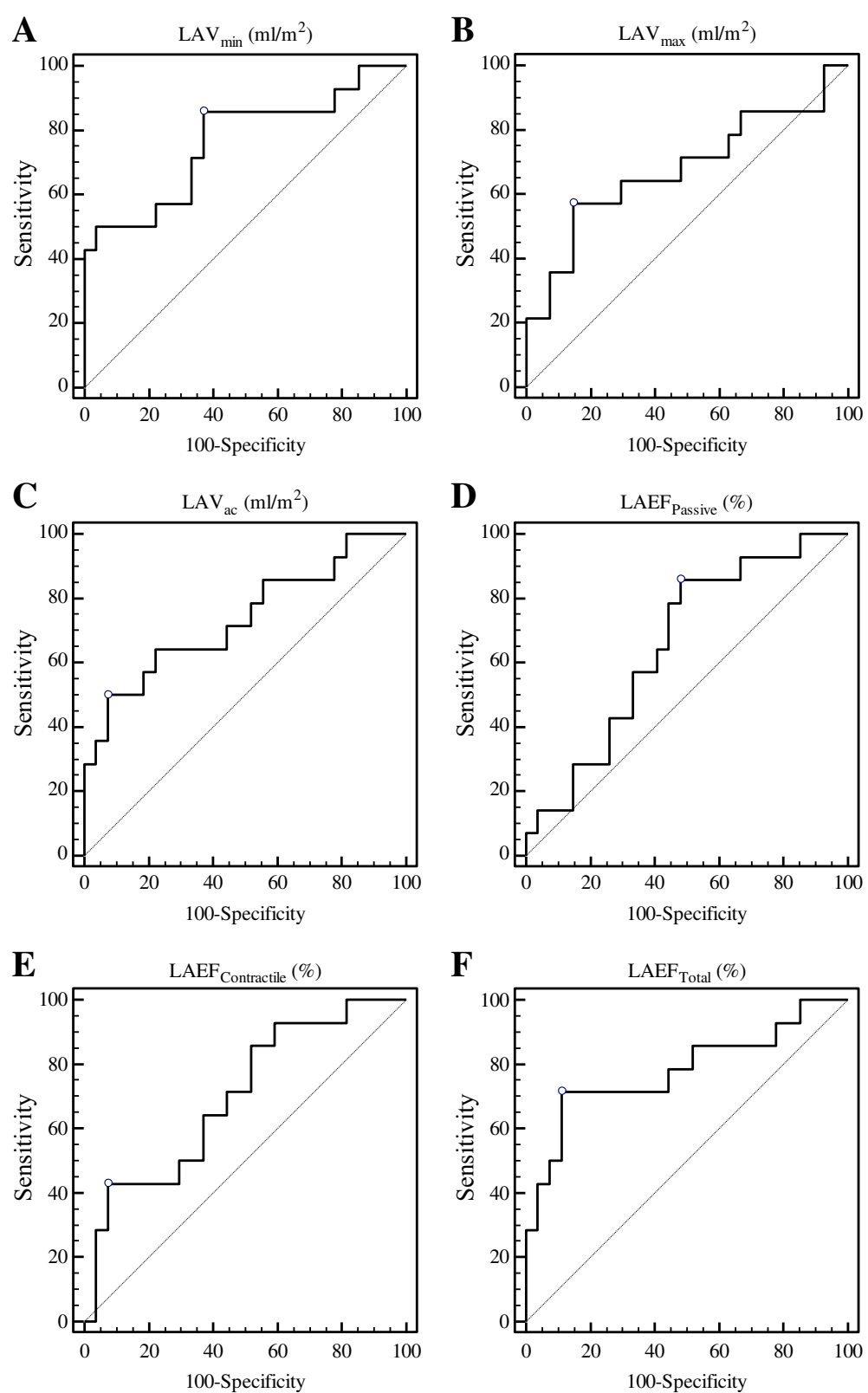

Figure 4 Area under the curves by receiver operator characteristic analysis assessing the relationships of the following left atrial indices to elevated left ventricular end diastolic pressure ( $>=12 \mathrm{mmHg}$ ): (A), left atrial volume at left ventricular end diastole ( $\mathrm{LAV}_{\text {min }}$ ); (B), left atrial volume at left ventricular end systole $\left(L A V_{\text {max }}\right) ;(C)$, left atrial volume at left ventricular late diastole before left atrial systole $\left(\mathrm{LAV}_{\mathrm{ac}}\right)$; (D), passive left atrial emptying function ( $\left.\mathrm{LAEF}_{\text {Passive }}\right) ;(\mathrm{E})$, active left atrial emptying function ( $\left.\mathrm{LAEF}_{\mathrm{Contractile}}\right)$; and (F), global left atrial emptying function ( $\left.\mathrm{LAEF}_{\text {Total }}\right)$. 
Table 3 ROC analysis assessing association of LA indices to increased LVEDP (>12 $\mathrm{mmHg}$ ) using single-phase method

\begin{tabular}{lccccc}
\hline & AUC & p-value & $\begin{array}{c}\text { Criterion } \\
\text { cutoff value }\end{array}$ & Sensitivity & Specificity \\
\hline $\mathrm{LAV}_{\min }$ & 0.765 & 0.002 & $\geq 23 \mathrm{ml} / \mathrm{m}^{2}$ & $86 \%$ & $63 \%$ \\
$\mathrm{LAV}_{\text {max }}$ & 0.677 & 0.074 & $\geq 54 \mathrm{ml} / \mathrm{m}^{2}$ & $57 \%$ & $85 \%$ \\
$\mathrm{LAV}_{a c}$ & 0.735 & 0.008 & $\geq 47 \mathrm{ml} / \mathrm{m}^{2}$ & $50 \%$ & $91 \%$ \\
$\mathrm{LAEF}_{\text {Passive }}$ & 0.656 & 0.077 & $\leq 17 \%$ & $86 \%$ & $52 \%$ \\
$\mathrm{LAEF}_{\text {Contractile }}$ & 0.698 & 0.022 & $\leq 16 \%$ & $43 \%$ & $93 \%$ \\
$\mathrm{LAEF}_{\text {Total }}$ & 0.780 & 0.001 & $\leq 35 \%$ & $71 \%$ & $89 \%$ \\
\hline
\end{tabular}

LAV from time-volume curves demonstrated the expected large phasic volume changes in normal subjects (Figure 3A), but the relative volume change was much smaller in patients with elevated LVEDP and large atrial volumes (Figure 3B). Bland-Altman plots showed small mean differences between single-phase and multi-phase volumes of $-3.7 \pm 10.9 \mathrm{ml} / \mathrm{m}^{2}, 0.1 \pm 7.2 \mathrm{ml} / \mathrm{m}^{2}$ and $-2.9 \pm$ $8.8 \mathrm{ml} / \mathrm{m}^{2}$ for $\mathrm{LAV}_{\text {max }}, \mathrm{LAV}_{\text {min }}$ and $\mathrm{LAV}_{\mathrm{ac}}$, respectively (Figure 5).

\section{Discussion}

In this study we demonstrated that increased LA volumes at three different cardiac cycle phases were all associated with increased LVEDP. While $\mathrm{LAV}_{\text {min }}$ was most sensitive to increased LVEDP, $L A V_{\text {max }}$ and $L A V_{\text {ac }}$ were more specific correlates of elevated LV filling pressure. Overall, $\mathrm{LAV}_{\text {min }}$ performed the best in stratifying LVEDP in ROC analysis. Of the three LA functional indices, $\mathrm{LAEF}_{\text {total }}$ was the best measurement to identify elevated

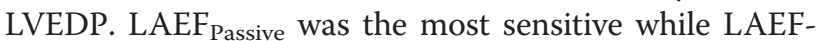
total and $\mathrm{LAEF}_{\text {contractile }}$ were more specific in stratifying elevated LVEDP. We also found that single-phase quantitation is a good alternative to the more laborious multi-phase quantitation method.

End systolic $\mathrm{LAV}_{\text {max }}$ has been shown previously to be a useful marker of LV diastolic function and a robust index of clinical outcome risk including atrial fibrillation, stroke, and heart failure [1-3,5,14-16]. One likely mechanism is LA remodeling in response to increased LV filling pressure [9]. Therefore a cross-sectional evaluation of LA size is viewed as a marker of LV filling pressure over time. Most published epidemiologic and clinical studies rely on maximal LA volume at LV end systole $\left(\mathrm{LAV}_{\max }\right)$ [13,14,17-19]. But a recent clinical study exploring the relationship of LA size at different cardiac cycle phases to clinical outcomes suggested that $\mathrm{LAV}_{\text {min }}$ taken at $\mathrm{LV}$ end diastole is superior to $\mathrm{LAV}_{\max }$ as a marker of clinical outcome risk [20]. Few studies have comprehensively assessed the relationship of phasic LA volumes and phasic LA function to LV filling pressures.
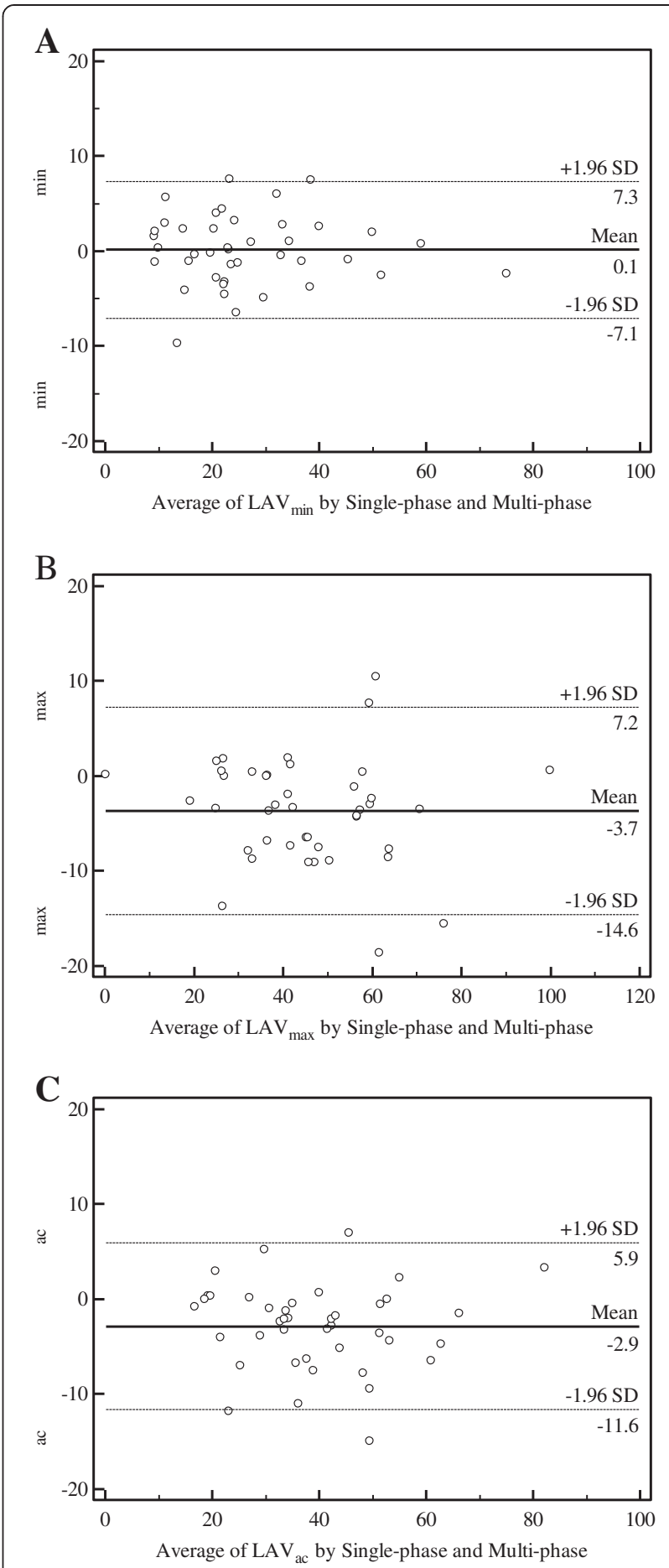

Figure 5 Comparisons of single-phase and multi-phase methods using Bland-Altman plots comparing single-phase and multi-phase methods in the assessment of left atrial volume at left ventricular end diastole $\left(\operatorname{LAV}_{\min }\right)(A)$, left atrial volume at left ventricular end systole $\left(\mathrm{LAV}_{\max }\right)(B)$; and left atrial volume at left ventricular late diastole before left atrial systole $\left(\mathrm{LAV}_{\mathrm{ac}}\right)(\mathrm{C})$. 
With the growing interest in LA assessment in clinical and epidemiological studies it is important to delineate the pros and cons of alternative evaluation methods $[7,9]$. The multi-phase method, which is considered to be the standard approach, is cumbersome and timeconsuming [11,12]. Furthermore, it can be difficult to identify LA phases from the time-volume curve when there is limited LA volume change in subjects with large LA volumes and poor LA function. The single-phase method, using 3 phases based on mitral valve position is widely used in clinical studies because of its simplicity [13]. However, published validation data is limited. We demonstrated that differences in LA volumes between two methods were small, while reproducibility of the single-phase method was excellent, supporting the use of single-phase approach. However, we acknowledge that our findings are limited to biplane-length approach only and can not be generalized to other method of LAV assessment.

There are limitations to our study. As expected the chronicity of increased LV filling pressures is a variable which may influence the extent of LA remodeling and LA active contraction and could not be easily determined in this clinical population. Mitral regurgitation was present in some patients and can further complicate the relationship of LA size and function to LV filling pressure. While all participants were reportedly stable small variation in hemodynamics are inevitable given that CMR was performed within 5 hours of catheterization. Contrast or sedatives commonly given during left heart catheterization may reduce LV filling pressure rendering a possible underestimation of the relationship of the LA indices with LVEDP. We also assessed LAV using the biplane area length method rather than the gold standard Simpson's rule method. However, the biplane method has been well validated and is of the most relevant approach because of its speed, simplicity and widespread use in both clinical and epidemiological studies.

\section{Conclusions}

In conclusion, increased LA volumes at multiple time points in the cardiac cycle and decreased LA functional indices were all associated with increases in LVEDP. Among them increased $\mathrm{LAV}_{\text {min }}$ and decreased $\mathrm{LAEF}_{\text {Total }}$ were most closely associated with elevated LVEDP in ROC analysis. Single-phase LA volume and function indices are good alternatives to the multi-phase volume curve methods.

\section{Abbreviations}

CMR: Cardiovascular magnetic resonance; LV: Left ventricle; RV: Right ventricle; LVEDP: Left ventricular End Diastolic Pressure; LA: Left atrium; $L A V$ : Left atrial volume; LAV max: Left atrial volume at left ventricular end systole; $L^{2} V_{\text {min }}$ : Left atrial volume at left ventricular end diastole; $L A V_{a c}$ : Left atrial volume at left ventricular late diastole before left atrial contraction;

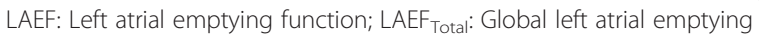

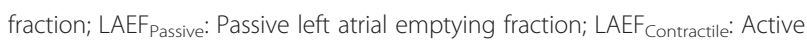
left atrial emptying fraction; ROC: Receiver operating characteristics.

\section{Competing interests}

The authors declare that they have no competing interests.

\section{Authors' contributions}

KP, Analysis and interpretation of the data, image analysis, and drafted manuscript. JM, Patient recruitment and clinical data management. PR, Patient recruitment and clinical data collection. LL, Image analysis. JC, Image acquisition. WS, Image acquisition. RG, Hemodynamic data collection. AB, Hemodynamic data collection. GP, Hemodynamic data collection. NR, Critical review of the manuscript. JJC, Conception and design of study, data review and analysis, critical review of the manuscript, and final approval of submission. All authors read and approved the final manuscript.

Received: 28 November 2012 Accepted: 21 October 2013

Published: 29 October 2013

\section{References}

1. Tsang TS, Barnes ME, Bailey KR, Leibson CL, Montgomery SC, Takemoto Y, Diamond PM, Marra MA, Gersh BJ, Wiebers DO, Petty GW, Seward JB. Left atrial volume: important risk marker of incident atrial fibrillation in 1655 older men and women. Mayo Clin Proc. 2001; 76:467-75.

2. Pritchett AM, Mahoney DW, Jacobsen SJ, Rodeheffer RJ, Karon BL, Redfield MM. Diastolic dysfunction and left atrial volume: a population-based study. J Am Coll Cardiol. 2005; 45:87-92.

3. Rossi A, Cicoira M, Zanolla L, Sandrini R, Golia G, Zardini P, Enriquez-Sarano M. Determinants and prognostic value of left atrial volume in patients with dilated cardiomyopathy. J Am Coll Cardiol. 2002; 40:1425.

4. Messika-Zeitoun D, Bellamy M, Avierinos JF, Breen J, Eusemann C, Rossi A, Behrenbeck T, Scott C, Tajik JA, Enriquez-Sarano M. Left atrial remodelling in mitral regurgitation-methodologic approach, physiological determinants, and outcome implications: a prospective quantitative Doppler-echocardiographic and electron beam-computed tomographic study. Eur Heart J. 2007; 28:1773-81.

5. Takemoto Y, Barnes ME, Seward JB, Lester SJ, Appleton CA, Gersh BJ, Bailey KR, Tsang TS. Usefulness of left atrial volume in predicting first congestive heart failure in patients $>$ or $=65$ years of age with wellpreserved left ventricular systolic function. Am J Cardiol. 2005; 96:832-6.

6. Beinart R, Boyko V, Schwammenthal E, Kuperstein R, Sagie A, Hod H, Matetzky S, Behar S, Eldar M, Feinberg MS. Long-term prognostic significance of left atrial volume in acute myocardial infarction. J Am Coll Cardiol. 2004; 44:327-34.

7. Patel DA, Lavie CJ, Milani RV, Shah S, Gilliland Y. Clinical implications of left atrial enlargement: a review. Ochsner J. 2009; 9:191-6.

8. Stefanadis C, Dernellis J, Toutouzas P. A clinical appraisal of left atrial function. Eur Heart J. 2001; 22:22-36.

9. Appleton CP, Galloway JM, Gonzalez MS, Gaballa M, Basnight MA. Estimation of left ventricular filling pressures using two-dimensional and Doppler echocardiography in adult patients with cardiac disease. Additional value of analyzing left atrial size, left atrial ejection fraction and the difference in duration of pulmonary venous and mitral flow velocity at atrial contraction. J Am Coll Cardiol. 1993; 22:1972-82.

10. Tsang TS, Barnes ME, Abhayaratna WP, Cha SS, Gersh BJ, Langins AP, Green TD, Bailey KR, Miyasaka Y, Seward JB. Effects of quinapril on left atrial structural remodeling and arterial stiffness. Am J Cardiol. 2006; 97:916-20.

11. Wen Z, Zhang Z, Yu W, Fan Z, Du J, Lv B. Assessing the left atrial phasic volume and function with dual-source CT: comparison with 3T MRI. Int J Cardiovasc Imaging. 2010; 26(Suppl 1):83-92.

12. Jarvinen V, Kupari M, Hekali P, Poutanen VP. Assessment of left atrial volumes and phasic function using cine magnetic resonance imaging in normal subjects. J Am Coll Cardiol. 1994; 73:1135-8.

13. Sievers B, Kirchberg S, Addo M, Bakan A, Brandts B, Trappe HJ. Assessment of left atrial volumes in sinus rhythm and atrial fibrillation using the biplane area-length method and cardiovascular magnetic resonance imaging with TrueFISP. J Cardiovasc Magn Reson. 2004; 6:855-63.

14. Kaminski M, Steel K, Jerosch-Herold M, Khin M, Tsang S, Hauser T, Kwong RY. Strong cardiovascular prognostic implication of quantitative left atrial contractile function assessed by cardiac magnetic resonance imaging 
in patients with chronic hypertension. J Cardiovasc Magn Reson. 2011: 13:42.

15. Barnes ME, Miyasaka Y, Seward JB, Gersh BJ, Rosales AG, Bailey KR, Petty GW, Wiebers DO, Tsang TS. Left atrial volume in the prediction of first ischemic stroke in an elderly cohort without atrial fibrillation. Mayo Clin Proc. 2004; 79:1008-14.

16. Gottdiener JS, Kitzman DW, Aurigemma GP, Arnold AM, Manolio TA. Left atrial volume, geometry, and function in systolic and diastolic heart failure of persons $>$ or $=65$ years of age (the cardiovascular health study). Am J Cardiol. 2006; 97:83-9.

17. Tsang TS, Gersh BJ, Appleton CP, Tajik AJ, Barnes ME, Bailey KR, Oh JK, Leibson C, Montgomery SC, Seward JB. Left ventricular diastolic dysfunction as a predictor of the first diagnosed nonvalvular atrial fibrillation in 840 elderly men and women. J Am Coll Cardiol. 2002; 40:1636-44.

18. Aurigemma GP, Gottdiener JS, Arnold AM, Chinali M, Hill JC, Kitzman D. Left atrial volume and geometry in healthy aging: the Cardiovascular Health Study. Circ Cardiovasc Imaging. 2009; 2:282-9.

19. Labovitz AJ, Williams GA, Redd RM, Kennedy HL. Noninvasive assessment of pacemaker hemodynamics by Doppler echocardiography: importance of left atrial size. J Am Coll Cardiol. 1985; 6:196-200.

20. Fatema K, Gertz MA, Barnes ME, Eisinger AD, Ness SA, Gersh BJ, Micallef IN, Seward JB, Cha SS, Bailey KR, Tsang TS. Acute weight gain and diastolic dysfunction as a potent risk complex for post stem cell transplant atrial fibrillation. Am J Hematol. 2009; 84:499-503.

doi:10.1186/1532-429X-15-99

Cite this article as: Posina et al:: Relationship of phasic left atrial volume and emptying function to left ventricular filling pressure: a

cardiovascular magnetic resonance study. Journal of Cardiovascular

Magnetic Resonance 2013 15:99.

\section{Submit your next manuscript to BioMed Central and take full advantage of:}

- Convenient online submission

- Thorough peer review

- No space constraints or color figure charges

- Immediate publication on acceptance

- Inclusion in PubMed, CAS, Scopus and Google Scholar

- Research which is freely available for redistribution 